\title{
An Online Training to Prepare Occupational Therapy Students to Work with Clients with Limited English Proficiency and Interpreters
}

Elizabeth A. Harrison

University of Illinois at Chicago

Mansha Mirza

University of Illinois at Chicago

Follow this and additional works at: https://encompass.eku.edu/jote

Part of the Bilingual, Multilingual, and Multicultural Education Commons, Higher Education Commons, Occupational Therapy Commons, and the Online and Distance Education Commons

\section{Recommended Citation}

Harrison, E. A., \& Mirza, M. (2018). An Online Training to Prepare Occupational Therapy Students to Work with Clients with Limited English Proficiency and Interpreters. Journal of Occupational Therapy Education, 2 (3). https://doi.org/10.26681/ jote.2018.020309 


\title{
An Online Training to Prepare Occupational Therapy Students to Work with Clients with Limited English Proficiency and Interpreters
}

\begin{abstract}
Effective communication between occupational therapists (OTs) and their clients is key to quality, clientcentered services. Most OTs can expect to work with clients with Limited English Proficiency (LEP). Language barriers may negatively impact client safety and client satisfaction. Working with language interpreters is a key means for OTs to best serve clients with LEP; however, few OT curricula provide adequate training in working with interpreters. This paper presents a new, innovative online training for preparing OT students to work with clients with LEP and interpreters. The brief online training used informational slides, video role plays and written case studies to prepare OT students to provide and advocate for quality services for clients with LEP. The training was evaluated by 26 second year MSOT students at a large, urban university. Student learning was assessed with a pre-test/post-test questionnaire. Pre-test results indicated that while most students $(86 \%)$ reported working with LEP clients on fieldwork, few (less than $27 \%)$ felt well prepared to do so. A majority (60\%) of students were unaware or unsure of how to access interpreter services at their fieldwork site. Post-test results indicate that the training significantly improved student knowledge, skills and attitudes for working with LEP clients and interpreters. The implications for OT education, including the importance and feasibility of training entry-level OT students to work with interpreters, are discussed. Opportunities for increased emphasis on cultural competence and language access education within future entry-level OTD curricula are highlighted.
\end{abstract}

\section{Keywords}

Interpreters, limited English proficiency, online education, cultural competence, language access

\section{Creative Commons License}

(c) (1) ()

This work is licensed under a Creative Commons Attribution-Noncommercial-No Derivative Works 4.0 License.

\section{Acknowledgements}

This training was developed as part of E. Harrison's doctoral project for her Doctorate of Occupational Therapy (OTD). The training is described in her unpublished doctoral project (Harrison, 2016) but is presented here in an updated format and with new data from an additional cohort of students. It is presented here with the consent of her advisor, Dr. Mirza. Our thanks to Dr. Yolanda Suarez-Balcazar and Dr. Yda Smith for serving on Dr. Harrison's OTD committee, to the students and pilot testers who evaluated this training, and to the two anonymous reviewers who provided comments on this manuscript. 


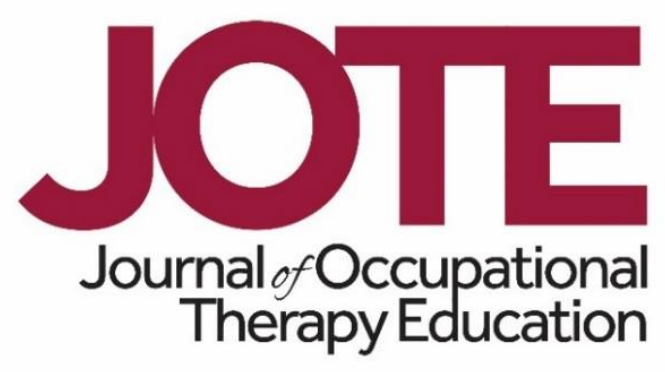

Volume 2, Issue 3

\title{
An Online Training to Prepare Occupational Therapy Students to
}

Work with Clients with Limited English Proficiency and Interpreters

Elizabeth Adare Harrison, OTD, OTR/L and Mansha Mirza, PhD, MSHSOR, OTR/L University of Illinois at Chicago

United States

\begin{abstract}
Effective communication between occupational therapists (OTs) and their clients is key to quality, client-centered services. Most OTs can expect to work with clients with Limited English Proficiency (LEP). Language barriers may negatively impact client safety and client satisfaction. Working with language interpreters is a key means for OTs to best serve clients with LEP; however, few OT curricula provide adequate training in working with interpreters. This paper presents a new, innovative online training for preparing OT students to work with clients with LEP and interpreters. The brief online training used informational slides, video role plays and written case studies to prepare OT students to provide and advocate for quality services for clients with LEP. The training was evaluated by 26 second year MSOT students at a large, urban university. Student learning was assessed with a pre-test/post-test questionnaire. Pre-test results indicated that while most students (86\%) reported working with LEP clients on fieldwork, few (less than $27 \%$ ) felt well prepared to do so. A majority (60\%) of students were unaware or unsure of how to access interpreter services at their fieldwork site. Post-test results indicate that the training significantly improved student knowledge, skills and attitudes for working with LEP clients and interpreters. The implications for OT education, including the importance and feasibility of training entry-level OT students to work with interpreters, are discussed. Opportunities for increased emphasis on cultural competence and language access education within future entry-level OTD curricula are highlighted.
\end{abstract}




\section{INTRODUCTION}

Individuals who have difficulty understanding, reading and expressing themselves in English are referred to as having "limited English proficiency" (LEP). As of 2010, approximately nine percent of the United States (US) population had LEP (Pandya, McHugh, \& Batalova, 2011). Most occupational therapists (OTs) and occupational therapy assistants (OTAs) can expect to work with clients with LEP.

Occupational therapists must communicate effectively with clients to determine occupational histories and goals, collaborate in treatment planning, and provide education. Language barriers can prevent OTs from performing these essential duties and providing client-centered care. Experts recommend utilizing trained interpreters as a feasible strategy for overcoming language barriers (Jacobs, Agger-Gupta, Chen, Piotrowski, \& Hardt, 2003; Karliner, Jacobs, Chen, \& Mutha, 2007). Accreditation Council for Occupational Therapy Education (ACOTE) standard B.4.23 directs that OT and OTA students at all levels (doctoral, master's, bachelor, and associate) should learn to "identify occupational needs through effective communication with patients, families, communities, and members of the interprofessional team," (ACOTE, 2018, p. 32). Optimal communication with patients, families, communities and even coworkers will often require use of interpreters in the case of individuals with LEP or individuals who are deaf. However, effective collaboration with language interpreters is a skill that requires training and practice, and few OT curricula provide students opportunities to learn about working with interpreters. The distinct nuances of OT practice require special consideration in training OTs to work with clients with LEP and language interpreters.

Language access (provision of appropriate interpretation and/or translation services) in healthcare is mandated by Title VI of the Civil Rights Act of 1964. Title VI applies to all healthcare entities that accept federal funding, including any site or provider who accepts Medicare, Medicaid, Children's Health Insurance Program (CHIP), or federal grants (Teitelbaum, Cartwright-Smith, \& Rosenbaum, 2012). Additional legislation also requires or encourages language access in healthcare, including the Hospital Survey and Construction Act, the Emergency Medical Treatment and Labor Act, and state legislation in several states (Mirza \& Harrison, 2018; Teitelbaum et al., 2012).

In medical encounters where the client has LEP and an interpreter is not provided, existing research shows that medical errors and misdiagnoses are more common, and adverse events have been shown to be up to 2.5 times more likely (Flores, Abreu, Barone, Bachur, \& Lin, 2012; Karliner et al., 2007). Clients with LEP who are not provided with interpreters are also at higher risk for readmissions and longer lengths of stay (Lindholm, Hargraves, Ferguson, \& Reed, 2012). In addition, such clients are less likely to receive client-centered care, have poorer compliance with follow-up care and recommendations, and report decreased satisfaction (Bender, 2002; Jacobs et al., 2003; Karliner et al., 2007; Teitelbaum et al., 2012). Fortunately, the use of professional interpreters has been shown to improve patient care to a level near or equal to the quality of care for English-speaking clients (Jacobs et al., 2003; Karliner et al., 2007). 
Despite the legal mandates for language access, risks of language barriers, and benefits of interpreter use, providers consistently underuse interpreters in practice (Diamond \& Jacobs, 2010; Ramirez, Engel, \& Tang, 2008; Schenker, Pérez-Stable, Nickleach, \& Karliner, 2011; Summers, Gonzalez, \& Pechak, 2015). One common barrier to professional interpreter utilization is overuse of untrained ad hoc interpreters, including family members and children (Lee et al., 2006; Ramirez et al., 2008). Clinicians' attitudes about perceived time, effort and costs of trained interpreter utilization pose additional barriers (Ramirez et al., 2008). Clinician training is a key step in improving language access in healthcare. Many clinicians and healthcare systems are unaware of their responsibilities to ensure language access (Chen, Youdelman, \& Brooks, 2007) and lack skills to change their behaviors (Diamond \& Jacobs, 2010).

Trainings have been developed in various disciplines to enhance clinicians' skills for interacting with clients with LEP (e.g. Diamond \& Jacobs, 2010; Summers et al., 2015). Clinician training can increase interpreter use and even improve patient satisfaction (Bischoff, Perneger, Bovier, Loutan, \& Stalder, 2003; Lee et al., 2006). Even brief trainings of under two hours have proven effective (Jacobs, Diamond, \& Stevak, 2010). Educators have also effectively used online trainings (e.g. Ikram, Essink-Bot, \& Suurmond, 2015; Kalet et al., 2005; Lie et al., 2009). However, most trainings are designed for physicians, and trainings specific to rehabilitation professionals are not widely available (Martinez \& Leland, 2015; Summers et al., 2015).

In response to the need for trainings relevant to the OT context, an online training was designed to instruct OT students in best practices when working with clients with LEP and language interpreters. The training was delivered to two cohorts of graduating OT students in the Master of Science (MS) program at a large urban university. Pretest/post-test questionnaires were used to evaluate the training.

\section{DESCRIPTION}

\section{Learning Theory}

This online training drew upon transformative learning theory (Merriam \& Bierema, 2013). Transformative learning is an approach that encourages students to question their pre-existing knowledge and assumptions, and come to new understanding of a concept, theory or situation. Transformative learning often presents students with scenarios of ethical complexity or injustice and aims to activate students to become agents of social change (Merriam \& Bierema, 2013). Case studies and videos encouraged students to think about the human consequences of language barriers. Then, students were provided with knowledge and skills to promote their development as change agents. Based on cultural competence education guidelines laid out by Betancourt (2003), learning objectives for the training were broadly categorized into three domains - knowledge, skills and attitudes. 


\section{Learners}

Participants were graduating second-year OT students at a large urban university, in the final weeks before receiving entry-level MS degrees in OT. All 38 students enrolled in the 2016 cohort, and all 46 students enrolled in the 2017 cohort, were invited to participate. Students in each cohort received information about the training via email and Blackboard near the end of their Level II fieldwork. The online training was presented as an optional learning activity and a resource to inform their in-class work during a week-long problem-based learning course that culminates the MS curriculum.

\section{Online Training}

The online training was self-paced and took approximately 45-60 minutes to complete. It included narrated informational slides, case studies, and video role-plays of interpreted OT encounters. The training was created in Microsoft PowerPoint and delivered via Blackboard learning management system. Informational slides drew from the author's clinical experience, past research, and review of relevant literature. Content covered included the legal context for language access in healthcare, information on health disparities experienced by clients with LEP, and evidence-based best practices for working with interpreters.

Three written case studies highlighted important ethical issues involving language barriers in the inpatient setting. After each case study, students were asked to consider how the OT and the hospital system could improve to address issues raised in the case. Case studies tackled safety risks of language barriers, ethical concerns with using family interpreters, and considerations for completing assessments with an LEP client.

Two multi-part video role plays showed an OT modeling how to respond to interpretation challenges and avoid communication breakdowns using assertive communication techniques. Videos were subtitled and featured a French-speaking client, a French-English interpreter, and an English-speaking OT. One video role play featured an in-person interpreter, while the second dealt with the use of a phone interpreter. Training contents are summarized in Table 1. Video scripts and other training content are described in more detail in the first author's unpublished doctoral project (Harrison, 2016). 
Table 1

Online Training Content

\begin{tabular}{|c|c|c|c|}
\hline$\frac{\text { Knowledge }}{\text { Content }}$ & Skills Content & $\frac{\text { Attitudes }}{\text { Content }}$ & Case Studies \\
\hline 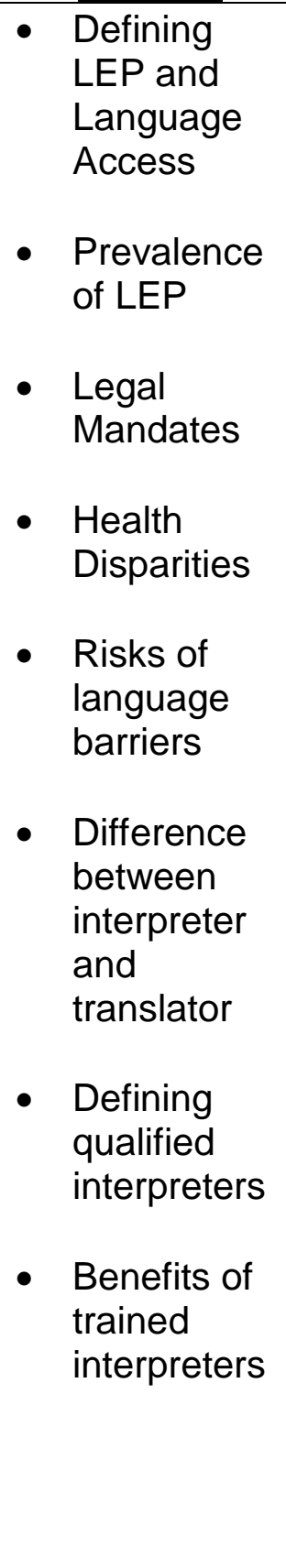 & $\begin{array}{l}\text { - Clinician self- } \\
\text { assessment of } \\
\text { non-English } \\
\text { language skills } \\
\text { - Selecting an } \\
\text { appropriate } \\
\text { interpreter } \\
\text { - Briefing and } \\
\text { debriefing with an } \\
\text { interpreter } \\
\text { How to access } \\
\text { interpreters in the } \\
\text { clinical setting } \\
\text { - Skills for clear and } \\
\text { assertive } \\
\text { communication to } \\
\text { avoid and/or } \\
\text { address } \\
\text { misunderstandings } \\
\text { Working with } \\
\text { phone interpreters } \\
\text { What to do when } \\
\text { there is no } \\
\text { interpreter } \\
\text { How to advocate } \\
\text { for interpretation } \\
\text { services at your } \\
\text { workplace }\end{array}$ & $\begin{array}{l}\text { - Relevance to } \\
\text { OT Code of } \\
\text { Ethics } \\
\text { - Effectiveness } \\
\text { of interpreters } \\
\text { in improving } \\
\text { care } \\
\text { - Importance to } \\
\text { client- } \\
\text { centered } \\
\text { practice } \\
\text { - Language } \\
\text { access as } \\
\text { ethical and } \\
\text { professional } \\
\text { duty }\end{array}$ & $\begin{array}{l}\text { - Video: OT } \\
\text { assertively } \\
\text { addressing } \\
\text { communication } \\
\text { barrier with in- } \\
\text { person interpreter } \\
\text { - Video: OT } \\
\text { troubleshooting } \\
\text { miscommunication } \\
\text { with phone } \\
\text { interpreter } \\
\text { Written: Risks and } \\
\text { limitations } \\
\text { associated with } \\
\text { relying on family } \\
\text { interpreters } \\
\text { Written: Effect of } \\
\text { inadequate } \\
\text { language access } \\
\text { when conducting } \\
\text { assessments } \\
\text { Written: Safety } \\
\text { risks of poor } \\
\text { language access }\end{array}$ \\
\hline
\end{tabular}




\section{In-person Case Study}

In the weeks following the release of the online training, students engaged in an in-class case study on the topic of language access and cultural competence. The case study was integrated into the students' culminating problem-based learning course. The case study built upon an existing cultural competence case in the course which described a Spanish-speaking immigrant client who misunderstood his rehabilitation prognosis. The first author added content to the existing case to reflect the language access issues at play. A small group of students prepared an in-service for the class based on their study of the case and associated resources. Students leading the in-service were instructed to summarize the case, develop a list of recommendations for improving cultural competence and language access, and create a resource guide for their classmates. Students were encouraged to use the online training as a resource in preparing for this in-service.

\section{ASSESSMENT}

\section{Ethics}

This project was approved by the Institutional Review Board of the University of Illinois at Chicago. Participants provided consent before completing the questionnaire evaluating the training.

\section{Pilot Testing}

The online training and questionnaire were pilot tested by three OTs and one first-year OT student. Pilot testers also provided informed consent. While completing the training and questionnaire, pilot testers were interviewed using the cognitive interview method (Willis, 2005). Pilot testers were asked to 'think aloud' as they noticed anything that they particularly liked, disliked or did not understand. They were also asked to comment on flow, content and presentation. The training and questionnaire were revised based on their feedback. Revisions were primarily focused on increasing ease of understanding and providing instructions for navigation. One question, "I knew how to access interpreter services at my fieldwork site," was added to the pre-test questionnaire based on recommendations from pilot testing.

\section{Pre-test/Post-test Questionnaire}

The final online training was evaluated using a pre-test/post-test online questionnaire, which included items related to students' knowledge, skills and attitudes about working with clients with LEP. Items were measured on a five point Likert scale with response options ranging from "Strongly Disagree" to "Strongly Agree". Some items were adapted from an existing questionnaire developed by Jacobs, Diamond and Stevak (2010), with written permission from the developers. Questions were added to reflect unique OT content and specific learning priorities. The questionnaire was delivered via Qualtrics online survey software. The post-test also included satisfaction questions and qualitative write-in questions allowing students to offer feedback about the training. 


\section{Data Analysis}

Quantitative data from the online questionnaire were analyzed in Microsoft Excel and in SPSS Software Version 24. Proportions were computed for all response categories (Strongly Disagree, Disagree, Unsure, Agree, and Strongly Agree) for each Likert scale item. Bar graphs were used to visually inspect and compare changes from pre-test to post-test. Next, the pre-test and post-test medians were compared using the Wilcoxon Related Samples Signed Rank test with a significance level set at .05. Qualitative responses were informally coded by the first author into conceptual categories. The second author corroborated interpretations of qualitative responses. Qualitative responses were used primarily to illustrate quantitative data and to record students' subjective feedback on the training experience.

\section{RESULTS}

Twenty-six participants completed the pre-test/post-test evaluation of the training (13 in 2016, and 13 in 2017). An additional four participants completed the pre-test measures only. All participants who completed pre-test $(\mathrm{N}=30)$ are included in results of background questions about fieldwork experiences which were asked only at pre-test, except for one question where there is missing data $(\mathrm{N}=29)$. However, only those who completed both pre-test and post-test $(\mathrm{N}=26)$ are included in pre and post-test comparisons. Results are presented below, sorted by question type.

\section{Fieldwork Experiences}

Participants were asked about fieldwork experiences at pre-test only. Twenty-nine participants responded to the question about frequency of working with clients with LEP on fieldwork. Of these, most participants reported working with clients with LEP 'sometimes (a few times per month)' (38\%, $\mathrm{n}=11)$ or 'frequently (weekly or several times per week)' $(28 \%, \mathrm{n}=8)$ on fieldwork. Remaining participants reported working with clients with LEP 'rarely' $(21 \%, n=6)$ or 'never' $(14 \%, n=4)$.

All 30 pre-test participants replied to the remaining questions about fieldwork. Twentyseven percent $(n=8)$ of these participants reported that professional interpreters were 'always' available when needed during fieldwork. Thirteen percent $(n=4)$ stated they were 'usually' available, and $37 \%(n=11)$ reported they were 'sometimes' available. Thirteen percent $(n=4)$ stated interpreters were only 'rarely' available and $10 \%(n=3)$ reported interpreters were never available when needed. When asked if they knew how to access interpreter services at their fieldwork site, a majority of participants $(60 \%$, $\mathrm{n}=18$ ) were unsure or unaware of how to access services.

\section{Knowledge}

Participants exhibited significant changes in scores for four knowledge items after completing the training, with results approaching significance for three additional items. Results are presented in Table 2. 
Table 2

Pre to Post-test Changes in Knowledge Items ( $\mathrm{N}=26)$

\begin{tabular}{|l|c|c|}
\hline Question & Direction of Change & $\begin{array}{c}\text { p- } \\
\text { value }\end{array}$ \\
\hline $\begin{array}{l}\text { I know the pros and cons of working with } \\
\text { different modes of interpretation (e.g. phone, } \\
\text { in-person). }\end{array}$ & Greater agreement & $<.001^{*}$ \\
\hline $\begin{array}{l}\text { Patients' family members or friends are usually } \\
\text { the best people to use as interpreters when } \\
\text { you and your patient do not speak the same } \\
\text { language. }\end{array}$ & Greater disagreement & $.003^{*}$ \\
\hline $\begin{array}{l}\text { Professional interpreters improve patient care. } \\
\text { Trained interpreters improve patient } \\
\text { safety. }\end{array}$ & Greater agreement & $.005^{*}$ \\
\hline $\begin{array}{l}\text { LEP individuals experience health disparities. } \\
\text { Provide interpreters to patients with LEP. }\end{array}$ & Greater agreement & .059 \\
\hline $\begin{array}{l}\text { Patients/clients with LEP should bring } \\
\text { someone with them who can interpret during a } \\
\text { clinic visit. }\end{array}$ & Greater disagreement & .063 \\
\hline $\begin{array}{l}\text { Language barriers may prevent patients from } \\
\text { receiving patient-centered care. }\end{array}$ & Greater agreement & .083 \\
\hline $\begin{array}{l}\text { It is inappropriate to use patients' family } \\
\text { members as interpreters. }\end{array}$ & No significant change & .109 \\
\hline $\begin{array}{l}\text { Health care facilies are legally required to } \\
\text { proant change }\end{array}$ & .755 \\
\hline
\end{tabular}


Participants' qualitative responses indicated intentions to use the knowledge gained for practical purposes. One student explained, "The presentation gave me tangible laws and regulations to bring to a future employer in the event I need to make an argument to increase availability of interpreters."

\section{Skills}

All thirteen skills-related questions exhibited statistically significant changes from pre to post. Results are summarized in Table 3, below.

Table 3

Pre to Post-test Changes in Skills Items $(\mathrm{N}=26)$

\begin{tabular}{|l|c|c|}
\hline Question & Direction of Change & $\begin{array}{c}p- \\
\text { value }\end{array}$ \\
\hline $\begin{array}{l}\text { I know how to intervene when interpretation is not } \\
\text { going well. }\end{array}$ & Greater agreement & $<.001^{*}$ \\
\hline $\begin{array}{l}\text { When working with an interpreter, it is important to } \\
\text { have a conversation with the interpreter before the } \\
\text { session. }\end{array}$ & Greater agreement & $<.001^{*}$ \\
\hline $\begin{array}{l}\text { When working with an interpreter, it is important to } \\
\text { have a conversation with the interpreter after the } \\
\text { session. }\end{array}$ & Greater agreement & $<.001^{*}$ \\
\hline $\begin{array}{l}\text { I feel well-equipped with skills to see patients with } \\
\text { in-person interpreters. }\end{array}$ & Greater agreement & $<.001^{*}$ \\
\hline $\begin{array}{l}\text { I feel well-equipped with skills to see patients with } \\
\text { phone interpreters. }\end{array}$ & Greater agreement & $<.001^{*}$ \\
\hline $\begin{array}{l}\text { I will keep LEP patients informed of any side } \\
\text { conversations I have with the interpreter. }\end{array}$ & Greater agreement & $.001^{*}$ \\
\hline $\begin{array}{l}\text { When speaking through an interpreter, it is } \\
\text { important to slow down and use short sentences. }\end{array}$ & Greater agreement & $.002^{*}$ \\
\hline $\begin{array}{l}\text { I will use visual aids when working with LEP } \\
\text { patients. }\end{array}$ & Greater agreement & $.002^{*}$ \\
\hline
\end{tabular}




\begin{tabular}{|l|l|l|}
\hline $\begin{array}{l}\text { I will ask for examples and give examples to } \\
\text { improve understanding when working with LEP } \\
\text { patients. }\end{array}$ & Greater agreement & $.002^{*}$ \\
\hline $\begin{array}{l}\text { I will ask LEP patients to repeat back my } \\
\text { instructions. }\end{array}$ & Greater agreement & $.003^{*}$ \\
\hline I will use LEP patients' family members to interpret. & Greater disagreement & $.007^{*}$ \\
\hline $\begin{array}{l}\text { I will use other staff members (e.g. students, } \\
\text { receptionists, aides, cleaning staff) to interpret. }\end{array}$ & Greater disagreement & $.020^{*}$ \\
\hline $\begin{array}{l}\text { I will check whether my LEP patients understand } \\
\text { my instructions. }\end{array}$ & Greater agreement & $.021^{*}$ \\
\hline
\end{tabular}

Participants' qualitative responses at post-test also highlighted new skills learned. One student reported, "Now I feel equipped with several practical skills that I can bring as a therapist, including initiating opening and closing conversations with the interpreter." Another student added, "I will seek out more visual aids, more teach backs, and more debriefings with interpreters." Participants' self-reported preparedness to work with interpreters also increased significantly, as illustrated in Figures 1 and 2.

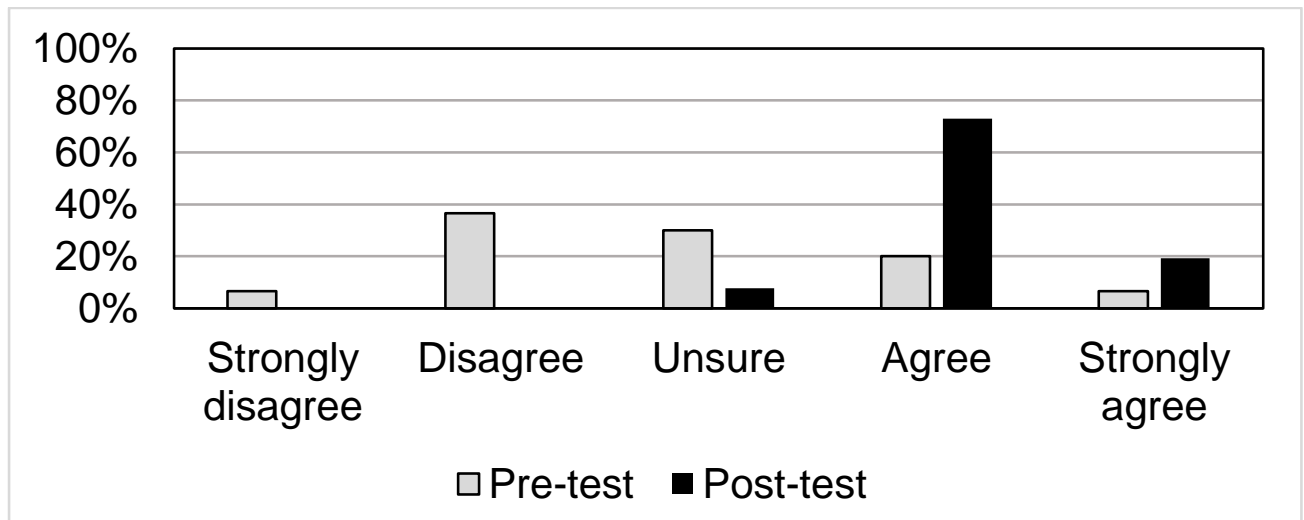

Figure 1. Pre-test/post-test responses to skills item, "I feel well-equipped with skills to see patients with in-person interpreters," $(\mathrm{N}=26)$. 


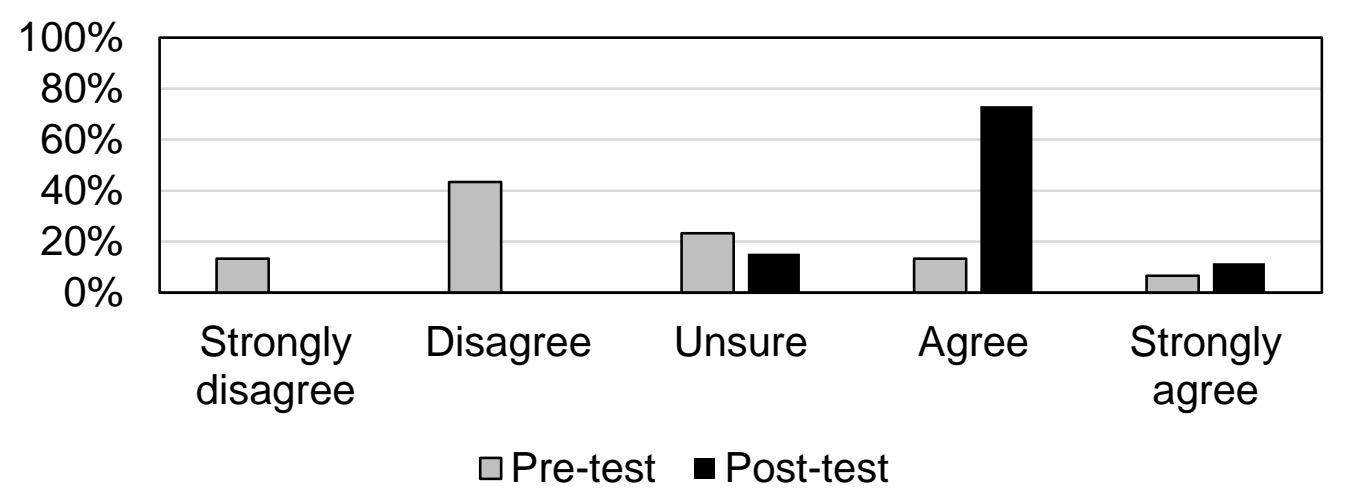

Figure 2. Pre-test/post-test responses to skills item, "I feel well-equipped with skills to see patients with phone interpreters," $(\mathrm{N}=26)$.

\section{Attitudes}

Participants' scores for five of the eight attitudes items changed significantly between pre-test and post-test. Two additional items were trending toward significance. Results are presented in Table 4, below.

Table 4

Pre to Post-test Changes in Attitudes Items ( $N=26)$

\begin{tabular}{|l|l|l|}
\hline Question & Direction of Change & $\begin{array}{c}p- \\
\text { value }\end{array}$ \\
\hline $\begin{array}{l}\text { I will arrange for a professional interpreter for } \\
\text { patients with LEP. }\end{array}$ & Greater agreement & $<.001^{*}$ \\
\hline It is easy to work with interpreters. & Greater agreement & $.001^{*}$ \\
\hline $\begin{array}{l}\text { The information I obtain using a trained medical } \\
\text { interpreter is accurate. }\end{array}$ & Greater agreement & $.002^{*}$ \\
\hline $\begin{array}{l}\text { Healthcare providers can have an impact on health } \\
\text { disparities experienced by LEP individuals. }\end{array}$ & Greater agreement & $.004^{*}$ \\
\hline $\begin{array}{l}\text { Using an interpreter is necessary when working with } \\
\text { patients who have LEP. }\end{array}$ & Greater agreement & $.008^{*}$ \\
\hline $\begin{array}{l}\text { Providing interpreters for LEP patients is part of my } \\
\text { ethical and professional duty. }\end{array}$ & Greater agreement & .059 \\
\hline
\end{tabular}




\begin{tabular}{|l|l|l|}
\hline $\begin{array}{l}\text { I think I will feel frustrated when caring for patients } \\
\text { with LEP. }\end{array}$ & Greater disagreement & .065 \\
\hline $\begin{array}{l}\text { I think I will find it rewarding to work with patients } \\
\text { with LEP. }\end{array}$ & No significant change & .132 \\
\hline
\end{tabular}

Qualitative responses suggested greater comfort both working with and advocating for interpreter services. One student explained, "I think I will feel more comfortable advocating for interpretation services in my workplace and using those services."

Evaluation of training. All participants completing post-test $(\mathrm{N}=26)$ agreed or strongly agreed that the training was helpful, valuable and of good quality. All participants also agreed that they would recommend the training to a classmate, with $73 \%(n=19)$ strongly agreeing.

Interest in further training. When asked if they would be interested in receiving more training about working with clients with LEP and interpreters, 15 of the 19 participants who responded said they would be interested in more training.

Preferred aspects. Twenty participants provided opinions about their favorite aspects of the training. Responses highlighted appreciation of the active learning experiences such as "videos", "case studies" and "multi-media", balanced with "clear and concise" didactic information. Eight participants reported the videos as a favorite aspect. Several appreciated the focus on "practical suggestions and tips," "resources" and "information about legal and ethical responsibilities." One student's comment summarizes this feedback,

"[l liked] the demonstration of how and why interpreters are important. The case studies illustrated these points well. And I appreciated the chance for active learning ("what are your solutions to these problems?") before seeing the answers on the next slide."

Suggestions for improvement. Seventeen participants provided suggestions. Several participants recommended including case studies representing diverse clinical settings beyond the inpatient rehabilitation setting. Some wanted more information about how to work around structural barriers and challenging situations, including time constraints for completing evaluations and times when interpreters are unavailable, "despite a hospital's solid efforts." Several hoped for more information about advocacy.

Use in future practice. Seventeen participants responded about the training's usefulness to their future practice. Responses focused on the practical and advocacy skills learned. Three student responses are particularly illustrative:

- "I think I will work with LEP patients in any setting that I choose, so I know this information will be useful." 
- 'It made me feel confident about advocating for my patients' needs when it comes to using interpreter services."

- "It gives me a mental framework and "checklist" of points to consider (briefing interpreter, visual aids, etc.) when working with a LEP client who needs an interpreter for safe, quality care."

Length. Eighteen participants commented on the length. Ten felt the training was appropriate length, while seven felt it was "a little too long." One respondent simply commented that they liked that it was self-paced. Of the participants who felt the training was too long, several suggested cutting down on didactic content while leaving videos and case studies intact.

\section{DISCUSSION}

This training was among the first online trainings about language access to be developed specifically for OT students. The pre-test/post-test questionnaire results suggest that this training produced significant improvements in student readiness to serve clients with LEP.

\section{Need for Training}

A key finding of the background questions is that $86 \%$ of participants reported working with clients with LEP on fieldwork ( $\mathrm{n}=25$ of total $\mathrm{N}=29$ ). This statistic is unsurprising given that $9 \%$ of US residents are LEP (Pandya et al., 2011), but nonetheless highlights how crucial it is for students to gain skills in working with clients with LEP. The participants completed their training in the last month of their OT education, near the end of their Level II Fieldwork experiences. However, only $27 \%$ of participants stated they felt well-equipped to see clients with in-person interpreters ( $n=8$ of total $N=30$ ), and only $20 \%$ stated that they felt well-equipped to work with phone interpreters ( $n=6$ of total $\mathrm{N}=30$ ). Researchers have found that providers tend to overestimate their skills in working across language barriers (Hudelson, Perneger, Kolly, \& Junod Perron, 2012), so such low rates of perceived skill should give pause. Scholars have also noted the dangers of Level II students missing signs of life-threatening conditions like autonomic dysreflexia due to poor interpreter utilization (Martinez \& Leland, 2015). This makes a strong case for training students before Level II Fieldwork.

Some might argue that interpreter utilization is one of many skills that should be modeled and taught by practicing clinicians while students are on fieldwork. However, scholars in the medical education literature (Ikram et al., 2015) point out that since under-utilization of interpreters is pervasive in the field, we cannot expect students to learn best practice from fieldwork. Pre-test data from this project indicate that OT students had not learned appropriate skills for working with interpreters from their fieldwork supervisors. The present gap in student training leaves both students and clients at risk. A brief online training such as this one could offer a practical and affordable solution to improve both patient and student outcomes. 


\section{Efficacy of Training}

The findings of this project echo findings from previous studies regarding effectiveness of online trainings in improving student knowledge and self-efficacy for working with interpreters (Ikram et al., 2015; Kalet et al., 2005). This brief educational intervention was effective in improving knowledge, skills and attitudes for working with interpreters. Past research indicates that increasing students' skills to work with interpreters is the most important way, alongside increasing student diversity, to improve student readiness to work with clients with LEP (Rodriguez, Cohen, Betancourt, \& Green, 2011).

Knowledge. After completing the training, participants demonstrated increased knowledge in several key areas. Participants were more likely to disagree with using family members as interpreters. Previous research has repeatedly identified overconfidence in ad hoc, untrained interpreters as a major barrier to utilization of professional interpreters (Ikram et al., 2015; Lee et al., 2006; Ramirez et al., 2008). As such, this knowledge is crucial to improving clinicians' interpreter use. After completing the training, participants were also more likely to agree they knew the pros and cons of working with in-person, phone and video interpreters. As phone and video interpretation become increasingly common, clinicians will need to develop clinical reasoning skills to select the most appropriate types of interpreters for their clients.

Skills. Both quantitative and qualitative results identified skills learning as a major strength of this training. Participants left the training with an expanded toolbox of evidence-based skills for working with interpreters, including briefing and debriefing with interpreters before and after the session, using visual aids, employing clarifying examples, and intervening when interpretation goes awry.

Attitudes. After training, participants were significantly more likely to agree that using an interpreter with clients with LEP is a necessary part of their ethical and professional duties. In addition, participants felt more confident that healthcare providers could have an impact on health disparities affecting persons with LEP. Each of these learning outcomes bode well for participants' future utilization of interpreters, and for possibly becoming champions of language access in their future workplaces.

Since perceived effort associated with interpreter use is a key barrier to utilization (Ramirez et al., 2008), participants might be less likely to use interpreters if they think it is difficult. The questionnaire item, "It is easy to work with interpreters" was the primary evaluation for this essential point. Despite learning a great deal more about the details of language access, at post-test participants were more likely to agree that working with interpreters is easy. This result could suggest a decrease in perceived effort, associated with a higher likelihood of future interpreter utilization. At post-test, participants were more likely to agree that they would request an interpreter for clients with LEP $(p<$ $.001)$, with $85 \%(n=22$ of total $N=26)$ stating they would 'always' arrange for an interpreter for clients with LEP. 
Student experiences. Participants were very positive about the training in their evaluations. All twenty-six of the participants agreed that the training would be valuable to their future practice and stated that they would recommend the training to a classmate. Participants enjoyed this addition to their coursework.

\section{Limitations}

Because this training was presented as an optional learning activity, it may have attracted a subset of students most interested in cultural competence. The questionnaire also reflects self-reported, short-term outcomes that may differ from skills demonstrated in long-term practice. The training focused on the inpatient rehabilitation setting and might be most applicable to work in that setting.

\section{Future Research}

Future research should further explore best practices for working with interpreters in diverse OT settings, so that these evidence-based recommendations can be incorporated into future trainings. In addition, future research could compare the effectiveness of different training methods, approaches, and timings to ensure that trainings about working with interpreters are optimally designed for OT students. Finally, future work should examine long-term outcomes of such trainings, and whether any refresher trainings might be recommended.

\section{IMPLICATIONS FOR OCCUPATIONAL THERAPY EDUCATION}

Existing literature shows that effective collaboration with interpreters is vital to improving quality of care and patient safety (Jacobs et al., 2003; Karliner et al., 2007). Preparing students to work with interpreters should be seen as a key entry-level requirement. Given this skill's importance to client-centered and safe OT practice, a learning objective about working with language interpreters should be included in future versions of the ACOTE standards. Effective collaboration with sign and spoken language interpreters could be explicitly included in the current ACOTE standard about communication, Standard B.4.23 (ACOTE, 2018).

This study showed the importance and feasibility of training OT students to work with clients with LEP and interpreters. This brief, low-cost, online training built student preparedness for working with this population. The transition to the entry level Doctorate of Occupational Therapy (OTD) provides an opportunity for OT schools to integrate this important content into their curricula. With the transition to the OTD, universities have the opportunity to prioritize the care of clients with LEP by adding training to better prepare students to work across languages. Educators can build upon the training described in this article, and perhaps add in-person role play practice working with interpreters, as suggested by one participant in this research and as recommended by other scholars (Diamond \& Jacobs, 2010). Such language access training could be integrated with enhanced cultural competence content and infused throughout the new OTD curriculum to prepare students before they enter practice. 
In addition to the training of OT students described in this paper, the first author has also used this training as the basis for continuing education trainings for practicing OTs in the form of a hospital in-service and a conference workshop. Other researchers have highlighted the importance of "training the trainers" (Ikram et al., 2015). Since practicing OTs are instructing students on fieldwork, it is important to spread evidence-based skills to those already working in the field. Trainings such as this one can be offered to employers as new hire orientations or as continuing education. In addition, universities could take the lead in offering continuing education courses about collaborating with clients with LEP and interpreters. Educating practicing clinicians is another mechanism to promote quality care for clients with LEP.

Communication is essential to providing occupational therapy services that are safe, effective and client-centered. Training OT students to work across language barriers is key to preparing our students to offer the best care possible.

\section{References}

Accreditation Council for Occupational Therapy Education (ACOTE). (2018). Standards and interpretive guide. Retrieved from https://www.aota.org/ /media/Corporate/Files/EducationCareers/Accredit/Standa rdsReview/2018-ACOTE-Standards-Interpretive-Guide.pdf

Bender, D. G. (2002). Physical therapy education in the new millenium: Patient diversity plays a pivotal role in the shaping of our professional future. Journal of Physical Therapy Education, 16(3), 8-13. https://doi.org/10.1097/00001416-200210000-00003

Betancourt, J. R. (2003). Cross-cultural medical education: Conceptual approaches and frameworks for evaluation. Academic Medicine, 78(6), 560-569. https://doi.org/10.1097/00001888-200306000-00004

Bischoff, A., Perneger, T. V., Bovier, P. A., Loutan, L. \& Stalder, H. (2003). Improving communication between physicians and patients who speak a foreign language. British Journal of General Practice, 53(492), 541-546.

Chen, A. H., Youdelman, M. K., \& Brooks, J. (2007). The legal framework for language access in healthcare settings: Title $\mathrm{VI}$ and beyond. Journal of General Internal Medicine, 22(S2), 362-367. https://doi.org.10.1007/s11606-007-0366-2

Diamond, L. C., \& Jacobs, E. A. (2010). Let's not contribute to disparities: The best methods for teaching clinicians how to overcome language barriers to health care. Journal of General Internal Medicine, 25(S2), 189-193. https://doi.org:10.1007/s11606-009-1201-8

Flores, G., Abreu, M., Barone, C. P., Bachur, R., \& Lin, H. (2012). Errors of medical interpretation and their potential clinical consequences: A comparison of professional versus ad hoc versus no interpreters. Annals of Emergency Medicine, 60(5), 545-553. https://doi.org/10.1016/j.annemergmed.2012.01.025

Harrison, E. A. (2016). Training occupational therapy students to collaborate with limited English proficient (LEP) clients and interpreters. (Unpublished doctoral project). University of Illinois at Chicago. 
Hudelson, P., Perneger, T., Kolly, V., \& Junod Perron, N. (2012). Self-assessed competency at working with a medical interpreter is not associated with knowledge of good practice. PLoS ONE, 7(6), e38973. https://doi.org/10.1371/journal.pone.0038973

Ikram, U. Z., Essink-Bot, M. L., \& Suurmond, J. (2015). How we developed an effective e-learning module for medical students on using professional interpreters. Medical Teacher, 37(5), 422-427. https://doi.org/10.3109/0142159X.2014.939579

Jacobs, E. A., Agger-Gupta, N., Chen, A. H., Piotrowski, A., \& Hardt, E. J. (2003). Language barriers in health care settings: An annotated bibliography of the research literature. Woodland Hills: The California Endowment.

Jacobs, E. A., Diamond, L. C., \& Stevak, L. (2010). The importance of teaching clinicians when and how to work with interpreters. Patient Education and Counseling, 78(2), 149-153. https://doi.org/10.1016/i.pec.2009.12.001

Kalet, A. L., Mukherjee, D., Felix, K., Steinberg, S. E., Nachbar, M., Lee, A., ... Gany, F. (2005). Can a web-based curriculum improve students' knowledge of, and attitudes about, the interpreted medical interview? Journal of General Internal Medicine, 20(10), 929-934. https://doi.org/10.1111/j.1525-1497.2005.0193.x

Karliner, L. S., Jacobs, E. A., Chen, A. H., \& Mutha, S. (2007). Do professional interpreters improve clinical care for patients with limited English proficiency? A systematic review of the literature. Health Services Research,42(2), 727-754. https://doi.org/10.1111/i.1475-6773.2006.00629.x

Lee, K. C., Winickhoff, J. P., Kim, M. K., Betancourt, J. R., Park, E.R., Maina, A.W., \& Weissman, J. S. (2006). Resident physicians' use of professional and nonprofessional interpreters: A national study. Journal of the American Medical Association, 296, 1050-1053. https://doi.org/10.1001/jama.296.9.1050

Lie, D., Bereknyei, S., Kalet, A., \& Braddock, C. (2009). Learning outcomes of a web module for teaching interpreter interaction skills to pre-clerkship students. Family Medicine, 41(4). Retrieved from http://escholarship.org/uc/item/5w14r19q.pdf

Lindholm, M., Hargraves, J. L., Ferguson, W. J., \& Reed, G. (2012). Professional language interpretation and inpatient length of stay and readmission rates. Journal of General Internal Medicine, 27(10), 1294-1299. https://doi.org/10.1007/s11606-012-2041-5

Martinez, J., \& Leland, N. (2015). Language discordance and patient-centered care in occupational therapy: A case study. OTJR: Occupation, Participation and Health, 35(2), 120-128. https://doi.org/10.1177/1539449215575265

Merriam, S.B. \& Bierema, L.L. (2013). Chapter five: Transformative learning. In Adult learning: Linking theory and practice (82-103). San Francisco: Jossey-Bass.

Mirza, M., \& Harrison, E. A. (2018). Working with clients with limited English proficiency: Mapping language access in occupational therapy. Occupational Therapy in Health Care, 1-19. https://doi.org/10.1080/07380577.2018.1434722

Pandya, C., McHugh, M., \& Batalova, J. (2011). Limited English proficient individuals in the United States: Number, share, growth, and linguistic diversity. Migration Policy Institute. Retrieved from http://www.migrationpolicy.org/research/limitedenglish-proficient-individuals-united-states-number-share-growth-and-linguistic 
Ramirez, D., Engel, K. G., \& Tang, T. S. (2008). Language interpreter utilization in the emergency department setting: A clinical review. Journal of Health Care for the Poor and Underserved, 19(2), 352-362. https://doi.org/10.1353/hpu.0.0019

Rodriguez, F., Cohen, A., Betancourt, J. R., \& Green, A. R. (2011). Evaluation of medical student self-rated preparedness to care for limited English proficiency patients. BMC Medical Education, 11(1), 1. https://doi.org/10.1186/1472-6920-11-26

Schenker, Y., Pérez-Stable, E. J., Nickleach, D., \& Karliner, L. S. (2011). Patterns of interpreter use for hospitalized patients with limited English proficiency. Journal of General Internal Medicine, 26(7), 712-717. https://doi.org/10.1007/s11606-010-1619-z

Summers, C., Gonzalez, E., \& Pechak, C. (2015). How should we prepare rehabilitation sciences students to work with low English-proficient Spanish-speaking patients? Journal of Allied Health, 44(2), E17-21.

Teitelbaum, J., Cartwright-Smith, L., \& Rosenbaum, S. (2012). Translating rights into access: Language access and the affordable care act. American Journal of Law \& Medicine, 38(2), 348-373. https://doi.org/10.1177/009885881203800205

Willis, G. (2005). Cognitive interviewing: A how-to guide. Thousand Oaks, CA: Sage. https://doi.org/10.4135/9781412983655 